\title{
Elastic adhesive bandage in low back pain in active and sedentary pregnant women living in Coari, Amazonas
}

\author{
Emanuela Moraes Silva Fernandes, Gabrielle Silveira Rocha Matos², Ercília de Souza Andrade², Cleuzenir Melo Nunes',
} Maria Luciana Moura de Matos', Thiago dos Santos Maciel²

\begin{abstract}
Background: Gestational low back pain is a limiting symptom, which interferes in the activities of daily living and quality of life. There are several scientific findings on the effectiveness and benefits of banding for low back pain, making it necessary to investigate effective and inexpensive non-pharmacological technologies. Objectives: The objective of this study was to compare the effect of elastic adhesive bandage $(E A B)$ in low back pain in active and sedentary pregnant women. Method: Study quasi-experimental, analytical with 33 pregnant women living in the city of Coari (AM). Socio-demographic, obstetrical data on health and low back pain were collected. The bandage was applied like "I", with two bands in the paravertebral region of the lumbar spine and should remain for 3 days. Pain intensity was assessed by visual analogue pain scale (VAS) during the initial evaluation and after 3 days of the application procedure. For purposes of analysis, the sample was divided into 2 groups: active and sedentary. The Wilcoxon test was used to compare the mean of the low back pain intensity before and after the application of the intra-group bandage. The mean intensity of low back pain after the application of bandaging between groups was analyzed by the Mann-Whitney $U$ test. Significance was accepted for $p \leq 0,05$. Results: The mean age was $24.24( \pm 6.39)$ and $75.8 \%$ reported low back pain at moderate intensity. The pain intensity after application of the $E A B$ was lower in both the active $(p=0.039)$ and the sedentary $(p=0.000)$. There was no difference in pain intensity on day 3 in intragroup analysis $(p=0.691)$. Conclusion: $E A B$ reduced the intensity of low back pain in both active and sedentary pregnant women, however, there was no difference in its effect when the groups were compared.
\end{abstract}

Keywords: Elastic Adhesive Bandage, Low Back Pain, Pregnancy.

\section{INTRODUCTION}

Pregnancy is a landmark event and with enriching moments for the woman and for those participating in this moment beside her. During this period her body goes through several transformations in order to prepare the woman for childbirth and lactation: they undergo anatomical, physiological and biochemical changes in several systems. At this stage it is common the appearance of pains, predominantly in the lumbar region and mainly in women who already presented the symptomatology before even the pregnancy period ${ }^{(1)}$. Gestational low back pain (LBP) is a limiting symptom, which interferes in the activities of daily living (ADL) and quality of life (QOL). This is the more common of all musculoskeletal disorders, and may lead to persistent disabilities, ranging from sudden and uncomfortable pain to intense and prolonged pain, and may be manifested with the presence or absence of irradiation to the lower limbs (2).

One of the factors that increase susceptibility to diseases during and after pregnancy is sedentary lifestyle. Sedentary

women have a considerable decline in physical fitness during pregnancy ${ }^{(3)}$, being the active lifestyle during this period associated with a better cardiovascular function, reduction of gestational diabetes mellitus and gestational hypertension, limited weight gain and reduction of musculoskeletal discomfort ${ }^{(4)}$.

Physiotherapy can help reducing discomfort through the regular performance of moderate exercises and thus assist restoring and adapting to a new body awareness ${ }^{(4)}$. In this context, there are methods for diagnosis and to contribute to the relief of LBP without the use of drugs during pregnancy, involving from healthy living habits such as physical activity practice, to specific physiotherapeutic treatment ${ }^{(5)}$.

And with regard to physiotherapeutic resources, the literature points beyond the kinesiotherapeutic exercises and postural correction, for the use of elastic adhesive bandage based on the principles of Kinesio Taping ${ }^{\circledR}$ (KT), which has been widely diffused among conventional therapeutic

Corresponding Author: Gabrielle Silveira Rocha Matos; Institute of Health and Biotechnology. Estrada Coari Mamiá, 305 - Sala 02 - Bloco Administrativo; UFAM University Campus; Bairro Espirito Santo; CEP: 69.460-000; Phone: +55 95 98110-9591 / +55 92 99131-1764. E-mail: gabrielle_srm@hotmail.com; gabrielle_srm@ufam.edu.br 2 Instituto de Saúde e Biotecnologia da Universidade Federal do Amazonas (UFAM), Coari (AM), Brasil.

Full list of author information is available at the end of the article

Financial support: Universidade Federal do Amazonas (UFAM)/Fundação de Amparo à Pesquisa do Estado do Amazonas (FAPEAM) through the Programa de Apoio a Iniciação Científica (PAIC).

Submission date 01 April 2018; Acceptance date 03 July 2018; Publication date 11 October 2018 
treatments ${ }^{(6,7)}$. Among several effects, Kenzo Kase, the KT's creator, affirms the reduction of pain by neural pathways, which in addition to providing correction of muscle function by strengthening weakened muscles, causes cutaneous stimulus that facilitates or limits movement, helps reduce edema by directing exudates towards the lymphatic and lymph nodes and promotes joint position correction by softening muscle spasms ${ }^{(6,7)}$. The bandage is a resource that has no active agents (medicaments), hypoallergenic, latex-free, with acrylic adhesive capacity and activated by body heat, developed with elastic polymer wrapped in $100 \%$ cotton fibers. Its particularities outperform the other tapes commonly used in bandages because it allows fast drying, longer use time and because it is thinner and more elastic with stretching longitudinally of its resting position or total elasticity of 120 to $140 \%$, which facilitates wrapping the better the tissues and joints ${ }^{(7)}$. Some studies prove its efficacy ${ }^{(2,5)}$, however the scientific evidence is limited and controversial regarding the hypoalgesic effect ${ }^{(8)}$.

(LBP) is a frequent symptom in pregnant women, characteristically limiting, and because of the diversity of scientific findings about the effectiveness and benefits of bandage for (LBP) as well as the need to evaluate effective non-pharmacological and low-cost health technologies, the present study aimed to evaluate the effectiveness of bandage as a therapy used for the relief of (LBP) in pregnant women comparing its effect in active and sedentary women.

\section{METHODS}

This longitudinal, quasi-experimental, analytical study was developed at the Institute of Health and Biotechnology, Campus Coari and at the Basic Health Units (UBS) of the adjacent neighborhoods of UFAM. Pregnant women between 12 th and 38th week of gestation older than 18 years with complaints of (LBP) of non-specific origin were enrolled in the study. Subjects were excluded if they removed the bandage, gave up on the participation, had history of the occurrence of musculoskeletal trauma during the period in which the bandage was used, had the presence of adverse reactions during treatment and had risk pregnancy. The volunteers were invited to sign the Informed Consent Form and began the evaluation through an interview questionnaire composed of socio demographic and obstetric data of health and (LBP), as well as the visual analogue pain scale (VAS).

(LBP) was confirmed by the "low back pain test", in which the pregnant was in orthostatism with the feet united parallel and flexing the trunk, tilting it forward until the moment the legs began to flex and it was considered as a positive reference to low back pain during the execution of this movement. The location of the pain occurred by indicating the point of pain in a drawing of the human figure presented to them. The intensity was verified by visual analogue pain scale (VAS), graded from 0 to 10 , in which 0 is the absence of pain and 10 is the worst pain imaginable. The pain evaluation was performed during the first contact and re-evaluated 72 hours after the application of the bandage. To categorize the intensity of pain, the following classification was considered: 0-3 was considered "mild pain", 4-7 "moderate pain" and 8-10 "intense pain".

The bandage used for this study was of the brand "Tmax adhesive bandage of Kinesio $5 \mathrm{~cm} \times 5 \mathrm{~m}$ ". Before the application, it was carried out the preparatory routine as the use of $70 \circ \mathrm{GL}$ alcohol on the skin to keep it clean and dry, without waste of oils or moisturizer. The bandage was applied using the "I" technique with two bands located in the right and left paravertebral region. The volunteers were asked to perform a trunk flexion for the application of the bandage, then asked to return to the orthostatic position. For the application, the base of the bandage was fixed at the height of the posterior superior iliac spine and then the tape was pulled towards the cephalic direction at moderate tension fixed at $25 \%$. The volunteers were instructed to remain with the bandage for 3 days and in case of skin irritation (hyperemia and pruritus) to remove it. To facilitate removal and not cause pain or damage to the skin it was indicated not to use any type of chemical and keep the skin dry during the process. On the 3rd day (approximately 72 hours) of the application, the researchers contacted the volunteers for reevaluation of pain intensity.

Statistical analysis of the data was performed using the Statistical Package for Social Sciences SPSS (SPSS Inc., Chicago, IL, USA) software version 20.0. To analyze the normality of the distribution of variables was performed a Shapiro-Wilk test, which indicated a non-parametric distribution of the obtained data. The data were expressed as mean, standard deviation, minimum and maximum values (quantitative variables) and absolute and relative frequencies (categorical variables) for the description of the sample. For the purposes of analysis, the sample was divided into 2 groups: active (physical activity practitioners) and sedentary (non-physical activity during pregnancy), and this information was reported by the volunteer. The Wilcoxon test for 2 paired samples was used to compare the mean of the low back pain intensity before and after the bandage application. To compare the mean intensity of the low back pain after the application of the bandage between the 2 groups was used the Mann-Whitney $U$ test for independent non-parametric samples. The level of significance was considered for $p \leq 0,05$.

The entire procedure was approved by the human research ethics committee of the Federal University of Amazonas, CAAE: 46940415.4.0000.5020 under protocol 2.019.752.

\section{RESULTS}

The study consisted of 33 pregnant women living in the Municipality of Coari (AM), predominantly married/stable union $(75.76 \%)$, housewives $(48.48 \%)$, who completed high school (69.7\%) and with family income up to a minimum wage (36.36\%). The mean age of the volunteers 
was $24.24 \pm 6.39$, subjects were between the first and fifth pregnancy with an average number of pregnancies of $1.97 \pm 0.98$. The sample description data are shown in table 1 . The results presented in table 2 demonstrate a reduced number of active women during gestation (15.2\%). (LBP) was present in $36.4 \%$ of women before pregnancy and during pregnancy most of them $(75.8 \%)$ reported (LBP) at moderate intensity. In Table 3, the mean of the pain intensity before $E A B$ application is higher than the mean of the (LBP) after EAB application in both active $(p=0.039)$ and sedentary $(p=0.000)$ women. There was no difference in the value of (LBP) in the 3rd day of the effect of the bandage on the physical activity profile of the pregnant women evaluated $(p=0.691)$. When comparing the intensity of pain on the 3rd day after the application of EAB between active and sedentary subjects we observed the same mean $(p=0.691)$, thus indicating a non-difference in the effect of bandage when compared between groups.

Table 1 - Characterization of the sample.

\begin{tabular}{|c|c|c|c|c|c|}
\hline & \multirow{2}{*}{$\frac{\text { Mean }}{24.24}$} & \multicolumn{2}{|c|}{ Standard Deviation } & Minimum & \multirow[t]{2}{*}{ Maximum } \\
\hline Age & & & & 18 & \\
\hline Body weight (Kg) & 66.01 & & & 53 & 87 \\
\hline Height $(\mathrm{Cm})$ & 157.29 & & & 150 & 168 \\
\hline Number of Pregnancies & 1.97 & & & 1 & 5 \\
\hline Number of Births & 0.85 & & & 0 & 4 \\
\hline Number of Abortions & 0.18 & & & 0 & 2 \\
\hline No. of Children Born Alive & 0.72 & & & 0 & 4 \\
\hline Education & High school & Incomplete college & College & Elementary school & Not informed \\
\hline $\mathrm{N}=(\%)$ & $23(69.7)$ & $5(15.15)$ & $1(3)$ & $3(9.09)$ & $1(3)$ \\
\hline Family income & Up to a wage & 1 to 2 wages & More than 2 wages & Not informed & \\
\hline $\mathrm{N}=(\%)$ & $12(36.36)$ & $4(12.12)$ & $8(24.24)$ & $9(27.27)$ & \\
\hline Occupation & Housewives & Student & Working & Not informed & \\
\hline $\mathrm{N}=(\%)$ & $16(48.48)$ & $9(27.27)$ & $4(12.12)$ & $4(12.12)$ & \\
\hline Marital Status & Stable union & Single & Not informed & & \\
\hline $\mathrm{N}=(\%)$ & $25(75.76)$ & $8(24.24)$ & $1(3)$ & & \\
\hline
\end{tabular}

Table 2. Characteristics of the low back pain and physical activity profile $(n=33)$.

\begin{tabular}{lcc}
\hline \multicolumn{1}{c}{ Variables } & Before Pregnancy & During the current pregnancy \\
\hline Physical Activity Practice & $17(51.5 \%)$ & $5(15.2 \%)$ \\
Presence of low back pain & $12(36.4 \%)$ & $33(100 \%)$ \\
Pain intensity & & $2(6.1 \%)$ \\
Mild & & $25(75.8 \%)$ \\
Moderate & $6(18.2 \%)$ \\
Intense & & $1(3 \%)$ \\
Use of pain medication & $32(97 \%)$ \\
$\quad$ Yes & & \\
No & &
\end{tabular}

Table 3. Intensity of low back pain between active and sedentary groups.

\begin{tabular}{lcccc}
\hline & Pain Before Applying EAB* & Pain after 3 days of the EAB* & $\mathbf{P}^{+}$ & $\mathbf{P}^{ \pm}$ \\
\hline Actives $(\mathbf{n}=\mathbf{5})$ & $5.20( \pm 0.83)$ & $1.25( \pm 1.00)$ & 0.039 \\
Sedentary $(\mathbf{n}=\mathbf{2 8})$ & $5.82( \pm 2.12)$ & $1.00( \pm 1.00)$ & 0.000 & $0.691^{\S}$ \\
Total average $(\mathbf{n}=\mathbf{3 3})$ & $5.72( \pm 1.97)$ & $1.21( \pm 0.99)$ & 0.000 & \\
\hline
\end{tabular}

Note: * in VAS score; + Wilcoxon test to 2 paired samples; $¥$ Mann-Whitney $U$ test for two independent non-parametric samples; $\S$ analysis of pain after 3 days of EAB application among active and sedentary groups. 


\section{DISCUSSION}

In the present study was observed a high prevalence of sedentary women during the gestational period. This finding is similar to that found in other studies on the subject. In a study conducted with 30 pregnant women, it was observed that during pregnancy none of the pregnant practiced physical activity, and only $6 \%$ of the volunteers reported being active before pregnancy ${ }^{(2)}$. Another study found that $21 \%$ of the pregnant women with (LBP), who were in their sample, practiced regular physical activity during pregnancy and $79 \%$ did not practice any physical exercise on a regular basis ${ }^{(9)}$. Information on sedentary lifestyle during pregnancy is alarming in Brazilian statistics: $12.9 \%$ reported some physical activity during pregnancy and only $4.7 \%$ of pregnant women are active throughout pregnancy ${ }^{(5)}$. In this sense, healthy pregnant women should be encouraged to perform mild to moderate exercise 3 to 5 times a week for 30 minutes or more because adherence to physical exercise programs, when performed correctly, has been shown to be effective in preventing increased body pain, even minimizing it ${ }^{5,10)}$.

Considering the inclusion criteria, all the evaluated women reported some type of (LBP). Its intensity manifested itself diversified, with a prevalence of moderate pain $(75.8 \%)$, followed by intense pain (18.2\%) during the gestational period in both active and sedentary women, similar to those data of Carvalho et al. (2011) (11) and Parreira (2013) (2) who found pain categorized as moderate to severe and moderate pain, respectively. In a case report, 2 pregnant women presented an average of 7.2 pain on the VAS scale (moderate pain) at the initial evaluation ${ }^{(6)}$, while another study conducted with 97 pregnant women, $68 \%$ reported low back pain, which was characterized as high intensity ${ }^{(12)}$.

The intensity of pain seems to vary when compared the present study with the cited studies ${ }^{(2,6,11,12)}$, however, all the results make clear that this characteristic determines a pain profile of concern in terms of physical health. The discrete variety between the results can be explained by the biotype diversity among the populations studied, which may influence the adaptive process of biomechanical changes during the gestational period. In this study, only one volunteer reported making use of pain relief medications during the initial interview, and it was not informed whether it was through medical prescription or self-medication, however, she had been advised not to use medication during the period she was using the bandage and thus avoid outcome bias and also the possibility of risks to the pregnancy cycle. There is an increasing tendency to the self-medication during the gestational period, a practice that should be performed with great caution, since it may be dangerous to the fetus ${ }^{(13)}$.

A study that sought to determine the prevalence of low back pain and describe its main characteristics in pregnant women conducted in the interior of the state of São Paulo states that the vast majority of pregnant women interviewed were not given guidance on what to do to prevent or minimize the lumbar symptom and it may have contributed to the aggravation of pain. The authors emphasize that the clarification regarding the relief of (LBP) and its aggravating factors is extremely important, noting that some discomforts due to low back pain may remain for up to three years after birth ${ }^{(9)}$. For this situation, it emphasizes the importance of postural orientation and health education as techniques for the prevention of gestational low back pain, as well as physical therapy as a means of reducing pain through the use of targeted exercises, techniques that reestablish body dynamics and modulate the sensation of pain without risk.

The effect of the bandage on pain intensity before and after its application when evaluated intragroup showed that there was a reduction in the level of (LBP) after the application of EAB. The present result is similar to the study of Parreira (2013) ${ }^{(2)}$ in which the efficacy of the method was observed after 48 hours of the first application in pregnant women, with decreased pain and functional disability.

Similar results were found by Silva and Miranda (2017) in a case report with 2 pregnant women, with a reduction in both pain intensity and the level of disability of the lumbar spine ${ }^{(5)}$. The reduction of (LBP) by the application of EAB in subjects with herniated disc was observed in a study, its effect was justified by the stimulation of existing receptors in the skin allowing to regulate afferent impulses and painful impulses due to the format of the adhesive tape, which resembles the skin ${ }^{(14)}$ i.e., pain is reduced by neurological suppression, relieving muscular tensions. There are several theories that justify the reduction of pain (15).

In a systematic review aimed to describe the principles of the $E A B$ method and mainly analyze the results of clinical trials with pain control groups, some hypotheses for the hypoalgesic mechanism were attributed to the application of $E A B$, the most cited were as follows: a) gate control theory, in which the tension provided by the tape generates afferent stimulation, facilitating the mechanism of inhibition of pain; b) the tape provides sensorimotor feedback that allows only movements that cause less mechanical irritation of the tissues, consequently less pain occurs; c) the possibility of improvement is due to increased circulation in the lesion region ${ }^{(8)}$. Thus, despite its widespread use in practice, the mechanism of action of the EAB is not fully understood and the scientific evidence is limited and controversial regarding the hypoalgesic effect ${ }^{(8)}$.

As a final outcome for this study, the intensity of (LBP) in pregnant women after the application of EAB was similar between the groups of active and sedentary women. Although the study of Toledo et al. (2013) ${ }^{(16)}$ showed that the physical activity is a preventive measure of pains and discomforts due to changes in pregnancy. In the present study, both active and sedentary women presented low back pain and the improvement occurred without any difference to the profile of physical activity reported by the volunteer, thus indicating that the effect of the EAB for the reduction of (LBP) is positive independent of the regular practice of physical activity. 
The improvement described in the present study was evaluated in the short term (72 hours), but clinical relevance should be considered when acute pain reduction effects may facilitate the application of a contra-intervention, such as regular physical activity, therapeutic exercises, electrotherapy and manual therapies, which justifies the use of EAB as a therapeutic technique for a treatment methodology and not the only resource to be used. The study of Parreira et al. (2013) (2) concluded that women who practiced a proposed physical activity methodology showed efficacy in the treatment of (LBP) during pregnancy, while reducing functional limitations with a positive impact on the quality of life compared to the group that received only guidelines during prenatal care. However, the authors emphasize that the group of physical activity that received the application of $E A B\left(K T^{\circledR}\right)$ in the lumbar spine proved statistically more efficient. A differential of the present work is its methodology of evaluation of the isolated effect of $E A B$ for (LBP) in pregnant women with the absence of a control group or other associated interventions, including a low number of women who reported using medication to reduce pain, which allows to evaluate the isolated effect of the $E A B$ technique and combines low cost and less risk of intercurrence to the pregnancy cycle.

\section{CONCLUSION}

There was a reduction of pain intensity according to the VAS applied three days after the intervention, changing the predominantly moderate pain to a mild pain classification. The findings point to the use of EAB as a therapeutic resource for pain relief in pregnant women, characteristically high efficiency, which can be presented as a safe alternative for this population, because it is a drug-free, low cost and rapid results method that can facilitate the physiotherapeutic treatment, predating and facilitating the effective development of a rehabilitation protocol regardless of the patient's level of physical activity.

It is concluded, therefore, that EAB produces effects of reducing nonspecific (LBP) in pregnant women, and this reduction occurs for both active and sedentary women.

\section{AUTHORS' CONTRIBUTION}

EMSF: Collecting, analyzing and interpreting data, writing; GSRM: Design and planning of the project, analysis and interpretation of data, writing; ESA: Critical review of the content, approval of the final version of the manuscript; CMN: Data collection, tabulation and analysis of data; MLMM: Data collection, tabulation, preparation of the draft; TSM: Critical review of the content, approval of the final version of the manuscript.

\section{CONFLICT OF INTEREST}

The authors declare no conflicts of interest.

\section{AUTHORS DETAILS}

${ }^{1}$ Curso de Fisioterapia da Universidade Federal do Amazonas (UFAM), Coari (AM), Brasil.

\section{REFERENCES}

1- Souza LA, Brugiolo ASG. Os Beneficios da Fisioterapia na Lombalgia Gestacional. Estação Científica Edição Especial “Fisioterapia”. 2012; 1:1-14.

2- Parreira F. Kinesiotaping versus Stretching Global Ativo na diminuição da dor lombar em grávida [tese]. Porto: Universidade Fernando Pessoa; 2013.

3- Lima FR, Oliveira N. Gravidez e exercício. Rev Bras Reumatol. 2005; 45(3):188-190

4- Surita FG, Nascimento SL, Silva JLP. Exercício físico e gestação. Rev Bras Ginecol Obstet. 2014;36(12):531-4.

5- Silva ACR, Miranda ACG. Eficácia do Kinesio Taping para alívio da dor lombar em gestantes: relato de casos. Rev Inspirar Movimento \& Saúde. 2017; 14 (3): 23-27.

6- Moreira LS, Andrade SR, Soares V, Avelar IS, Amaral WN, Vieira MF. Alterações posturais, de equilíbrio e dor lombar no período gestacional. Femina. 2011;39(5):241-4.

7- Artioli DP, Bertolini GRF. Kinesio taping: aplicação e seus resultados sobre a dor: revisão sistemática. Fisioter Pesq. 2014;21(1):94-9.

8- Santos MM, Gallo AP. Lombalgia gestacional: prevalência e características de um programa pré-natal. Arquiv Bras Cien Saude. 2010; 35(3):174-9.

9- Castro KVB, Silva ALS, Lima JMMP, Nunes WJ, Calomeni MR, Silva VF. Fisiomotricidade e limiares de dor: efeitos de um programa de exercícios na autonomia funcional de idosas osteoporóticas. Fisioter Mov. 2010; 23(1):161-72.

10- Malmqvist S, Kjaermann I, Andersen K, Okland I, Bronnick K, Larsen JP. Prevalence of Low Back and Pelvic Pain During Pregnancy in a Norwegian Population. J Manipulative Physiol Ther. 2012; 35(4):272-8.

11- Carvalho VOMPBR, Gontigo LB, Teixeira S, Silva JG, Orsini M, Machado DCD, et al. Estabilização segmentar vertebral no controle da dor lombar crônica: efetividade e variações. Fisioter Bras. 2011. 12(3):227-31.

12- Galato D, Schraib RB, Marques LR, Brito ES. Perfil do uso de medicamentos durante a gravidez de puérperas internadas em um Hospital do Brasil. Rev Bras Farm Hosp Serv Saúde. 2015; 6: 24-9.

13- Oliveira LR, Mejia DPM. O efeito da bandagem funcional elástica na dor lombar [monografia online]. Brasil: Faculdade Ávila. [acesso em 2017 Nov 16]. Disponível em: http://portalbiocursos.com.br/ohs/data/ docs/32/75_-_O_efeito_da_bandagem_funcional_elYstica_na_dor_ lombar.pdf.

14- Alonso AC, Santos LR, Baron C, Ayama S, Junior GBV. O efeito do uso da bandagem funcional no tratamento da dor lombar em costureiras, estudo piloto. Rev CPAQV. 2015; 7(1): 1-8.

15- Toledo DRS. Efeito do exercício físico na dor lombar e nos desconfortos da gravidez. Revista Educação Física UNIFAFIBE. 2013; 2(2):3-12. 